\title{
HBV Vaccine Used
}

\section{Deschamps $\mathrm{F}^{*}$}

Department of Occupational Health, 51 Rue Cognac Jay, 51100 Reims, France

*Corresponding author: Deschamps F, Department of Occupational Health, 51 rue Cognac Jay, 51100 Reims, France, Tel: 0326788933; E-mail: mphilippot@chureims.fr

Received date: 21 August 2014; Accepted date: 29 October 2014; Published date: 05 November 2014

Copyright: (c) 2014 Deschamps F. This is an open-access article distributed under the terms of the Creative Commons Attribution License, which permits unrestricted use, distribution, and reproduction in any medium, provided the original author and source are credited.

\section{Abstract}

Background: Infection with hepatitis B virus (HBV) can be prevented by vaccination with HB surface antigen, which induces HBS specific antibodies and T cells. But the immunization status of workers and its relationship with occupational factors are not well documented. The goal is to examine the factors of risk and the immunization status against HBV among a population of workers.

Methods: An assessment of the vaccination and the immunization status against HBV was conducted among a miscellaneous population of French workers, recruited from a medical occupational center, during a cross-sectional study. A representative sample of a population of 3000 workers enrolled, was selected.

Results: The population studied included many housemaids (18\%), police officers (15\%), technicians (15\%), administrative agents (15\%), electricians (12\%) and healthcare workers $(6 \%)$. The overall vaccination coverage (against HBV) was $39 \%$, with an average of 4.2 doses of vaccine per worker. But the immune status was known for $18 \%$ of the studied population of which $2 / 3(12 \%$ of the whole population) where immunized against HBV. Elevated risk factor to be infected by HBS concerns $6 \%$ of the studied workers (half of them where immunized). Medium risk concerns $30 \%$ of the whole population (1/3 was immunized) and low risk enrolled $64 \%$ (nobody was immunized).

Conclusion: It is known that the high risk of infection among healthcare workers is greater than the general working population; but most of workers with medium occupation risk exposure were not immunized. Vaccination programs against HBV should be enforced for this last population.

The novelty of this study is to underline that only a restricted group of workers exposed to HBV risk contamination is immunizated.

Keywords: Workers; Hepatitis B; Immunization rate

\section{Introduction}

Infection with hepatitis $\mathrm{B}$ virus $(\mathrm{HBV})$ can be prevented by vaccination [1].

The vaccination status of workers and its relationship with occupational factors are usually not well documented [2]. Routine HBV vaccination programs targeted to high-risk group (but less frequently to medium and low risk groups) are generally considered as a key element in order to prevent strategies [3-5]. However, the low rate of natural immunization among adults in western countries must be taken into account.

So as to permit the availability of an effective vaccine and the substantial evidence of the transmission of $\mathrm{HBV}$, for example from healthcare workers to patients, this should be a condition of employment for workers undertaking intensive procedures, which are immunized against HBV.

Generally HBV is only transmissible through certain limited means; therefore an occupational transmission is rare [6]. But there is still considerable ignorance about the risks of contracting infection because of $\mathrm{HBV}$. It is widely perceived as being contagious, transmissible by casual and accidental contact in everyday life-despite good evidence proving the contrary. It is confirmed that HBV infection is concentrated in-but not confined to - certain high occupational risk groups, and consequently the prevalence of infection in low-risk groups remains low.

The HBV is only transmissible through certain limited means and, in the vast majority of jobs; there is neither a risk of workers becoming infected, nor risk of transmitting the infection to other workers. As a consequence, education about HBV infection for all employees is very important. It is important to highlight that individuals with HBV infection often remain asymptomatic for many years, and even with symptoms, they are often in a good shape to continue working.

It is clear that $\mathrm{HBV}$ is very much more transmissible than a lot of other viruses. For example, the risk of transmission of HBV, after a single infected person, is about 30\% [7]. Occupational physicians have an important role in the management of prevention of $\mathrm{HBV}$ contamination. It seems important to underline the main elements of a policy on $\mathrm{HBV}$ in the workplace:

- Background information about ways of transmission, lack of risk in the workplace

- Employment policy regarding HBV towards job applicants

- Statement on program of education for staff about HBV issues. 
Page 2 of 3

The goal of this study is to examine factors of risks distribution facing and the immunization status against $\mathrm{HBV}$ among a population of workers.

\section{Methodology}

An assessment of the vaccination and the immunization against HBV were conducted among a miscellaneous population of French workers, including housemaids, police officers, technicians, administrative agents, electricians, healthcare workers and some other jobs. All the workers were recruited from a medical occupational centre, during a cross-sectional study. A questionnaire including data about HBV immunization was administered. These data was completed by information obtained from their occupational medical file. Compliance with preventive practices against HBV infection was also assessed. Then, a representative sample of a population of 3000 workers enrolled was selected. An assessment of their risk level of contamination to $\mathrm{HBV}$ during their working time was done.

The characteristics of their occupational exposure to HBV were evaluated if possible, as well as their perception of a risk of occupationally acquired infections. Main barriers to vaccination were also taken into account. Data was analysed and the chi-square test was used, if necessary, for statistical association with a P-value of 0.05 .

\section{Results}

The duration of vaccine-induced protective immunity is poorly defined, especially for workers who were vaccinated as adults. The participation rate of that study was $100 \%$. The occupational risk of contracting Hepatitis B infection was different in relationship with job characteristics. The major barrier reported among most of the workers who were not vaccinated was a combination of a lack of opportunity and the fear of side effects of the vaccines. The major suggested ways to increase the vaccination rate was on the merits of vaccination.

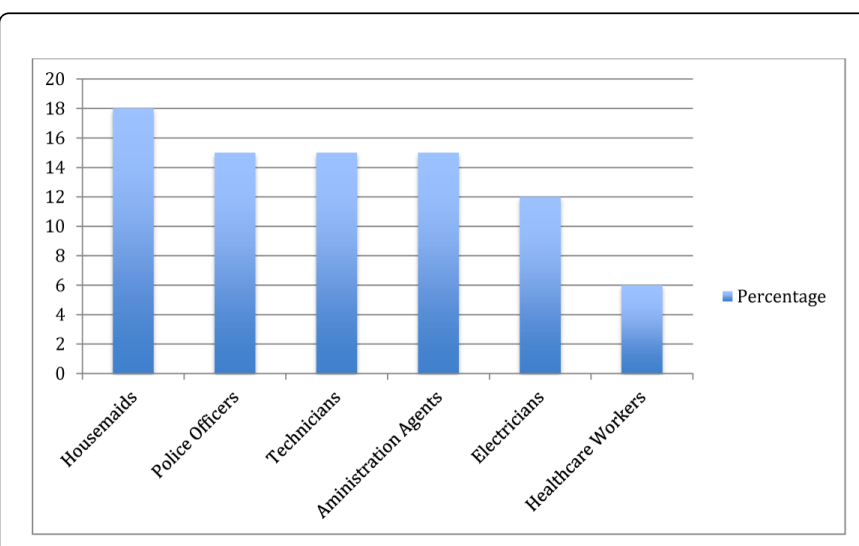

Figure 1: Main jobs included in the study. NB: 19\% of the workers belonging to the studied population had other occupation.

The population studied included essentially housemaids, police officers, technicians, administrative agents, electricians and healthcare workers (Figure 1). The overall vaccination coverage (against HBV) was $39 \%$ with an average of 4.2 doses of vaccine per worker. The number of doses of vaccine was detailed in the Table 1 . But the immune status was known for $18 \%$ of the studied population of which $2 / 3$ (12\% of the whole population) were immunized against HBV.
Elevated risk factor to be infected by HBV concerned essentially healthcare workers. Medium risk concerns $30 \%$ of the whole population, and low risk for most of them. Immunization against HBV in relationship with risk exposure level is shown in Table 2.

\begin{tabular}{|l|l|}
\hline Injections & Percentage \\
\hline Only $\mathbf{1}$ & $8.4 \%$ \\
\hline Between 2 and 3 & $66.6 \%$ \\
\hline Over 4 & $25 \%$ \\
\hline
\end{tabular}

Table 1: Number of injections against Hepatitis B.

\begin{tabular}{|l|l|l|}
\hline \multicolumn{2}{|l|}{ Risk exposure level } & Immunization against HBV \\
\hline High & $6 \%$ & $50 \%$ \\
\hline Medium & $30.3 \%$ & $30 \%$ \\
\hline Low & $63.7 \%$ & $0 \%$ \\
\hline
\end{tabular}

Table 2: Immunization against HBV in relationship with risk exposure level.

\section{Discussion}

We confirmed the results obtained in other studies, showing that the specific knowledge of workers about HBV and the severity of these diseases are proved to be unsatisfactory [4]. The policies regarding $\mathrm{HBV}$ vaccination, $\mathrm{HBV}$ carriage and response to $\mathrm{HBV}$ vaccination were variables sometimes inappropriate and no sufficiently comprehensive to protect exposed workers against occupationally acquired $\mathrm{HBV}$.

This emphasizes the need for a comprehensive, consistently applied, coordinated vaccination policy to ensure that workers received proper protection against HBV infection.

This study confirmed [5] the low prevalence of complete Hepatitis $B$ vaccination. Improvement in uptake following the respondent's recommendations will serve as a template in developing successoriented strategies among stakeholders.

Despite a very small proportion of workers is susceptible to contract HBV infection in our study, other studies [3] suggest that, in a global approach to prevent occupational infection by pathogens, a universal Hepatitis B vaccination of all workers is still considered as a priority. Obviously the greatest impact on the risk will most likely be achieved by focusing efforts on primary prevention strategies to reduce occupational HBV exposure.

Many professional organisations have developed recommendations, guidelines, standards and regulations for limiting exposures to a variety of occupational and environmental contaminants including $\mathrm{HBV}$, but this is not enough.

Despite a quite good knowledge about HBV infection and vaccine, most of workers are still not vaccinated. Hepatitis B should be a prerequisite for working in most jobs. The evaluation of costeffectiveness concerning immunization against Hepatitis $B$, indicate the reducing of the cost of treatment of Hepatitis B inducing chronic diseases including cancers [8]. There is a need of periodic training 
programs or occupational hazards as well as a vaccination of all workers with three doses of Hepatitis B vaccine.

It is known that the high risk of infection among healthcare workers is greater than the general working population, but most of the workers with medium occupation risk exposure were not immunized.

Vaccination programs against HBV should be again enforced for this last population.

\section{Conclusion}

The novelty of this study is to underline that only a restricted group of workers exposed to HBV risk contamination is immunizated.

\section{References}

1. Werner JM, Abdalla A, Gara N, Ghany MG, Rehermann B (2013) The hepatitis B vaccine protects re-exposed health care workers, but does not provide sterilizing immunity. Gastroenterology 145: 1026-1034.

2. Ziglam H, E-Hattab M, Shingheer N, Zorgani A, Elahmer O (2013) Hepatitis B vaccination status among healthcare workers in a tertiary care hospital in Tripoli, Libya. J Infect Public Health 6: 246-251.
3. Pellissier G, Yazdanpanah Y, Adehossi E, Tosini W, Madougou B, et al. (2012) Is universal HBV vaccination of healthcare workers a relevant strategy in developing endemic countries? The case of a university hospital in Niger. PLoS One 7: e44442.

4. Wicker S, Rabenau HF, von Gierke L, François G, Hambach R, et al. (2013) Hepatitis B and influenza vaccines: important occupational vaccines differently perceived among medical students. Vaccine 31: 5111-5117.

5. Azodo C, Ehizele A, Uche I, Erhabor P (2012) Hepatitis-B vaccination status among dental surgeons in benin city, Nigeria. Ann Med Health Sci Res 2: 24-28.

6. Antony J, Celine T (2014) A Hospital-based Retrospective Study on Frequency and Distribution of Viral Hepatitis. J Glob Infect Dis 6: 99-104.

7. de la Briére A, Berenguerb M, Destombesa C (2013) Prevention and vaccination against hepatitis. Soins: 29-31.

8. Montella E, Schiavone D, Apicella L, Di Silverio P, Gaudiosi M, et al. (2014) Cost-benefit evaluation of a preventive intervention on the biological risk in health: the accidental puncture during the administration of insulin in the University Hospital "Federico II" of Naples. Ann Ig 26: 272-278. 